\title{
Experimental Study on Structural Performance of RC Exterior Beam-Column Joints Retrofitted by Steel Jacketing and Haunch Element under Cyclic Loading Simulating Earthquake Excitation
}

\author{
Cong-Thuat Dang and Ngoc-Hieu Dinh \\ The University of Danang: University of Science and Technology, Da Nang, Vietnam \\ Correspondence should be addressed to Cong-Thuat Dang; dangcongthuat@dut.udn.vn
}

Received 7 February 2017; Accepted 11 May 2017; Published 7 June 2017

Academic Editor: Christophe Petit

Copyright @ 2017 Cong-Thuat Dang and Ngoc-Hieu Dinh. This is an open access article distributed under the Creative Commons Attribution License, which permits unrestricted use, distribution, and reproduction in any medium, provided the original work is properly cited.

\begin{abstract}
Several retrofitting methods for reinforced concrete (RC) beam-column joints in old buildings without seismic details were developed. Four half-scale RC exterior beam-column joints were fabricated and tested under cyclic loading simulating earthquake excitation. The control specimen was designed to fail in joint shear. Two practical retrofitting strategies were applied to the control specimen which consider the architectural characteristic in real buildings, including steel jacketing and haunch retrofit solution. The structural performance of the test specimens was investigated in terms of various factors including damage and failure, loaddrift relationship, ductility, dissipated energy, and strain profiles of longitudinal reinforcement. Experimental results confirmed that the proposed retrofit methods were shown to enhance the seismic capacity of the joints in terms of the strength, deformation capacity, and energy dissipation capacity while the shear deformation in the panel zone significantly reduced in comparison with the control specimen.
\end{abstract}

\section{Introduction}

Existing reinforced concrete (RC) buildings in many developing countries had been traditionally designed to resist mainly gravity loads and wind loads without properly considering the seismic effects that pose a significant risk to human beings. In those buildings, beam-column joints have nonseismic reinforcement details. According to a previous report [1], the beam-column joints without seismic reinforcement details have been found to be susceptible to failure due to earthquakes which could contribute to partial or entire collapse of concrete buildings. Therefore, to ensure the safety of the existing RC buildings, it is essential to improve the strength and ductility of beam-column joints. From the observations of structural failure due to earthquakes, corner and exterior concrete beam-column joints have been recognized as the most vulnerable parts of RC frames due to the discontinuity in beam, weak concrete confinement inside the joint, and unreliable load-transferring mechanism dependent on concrete tensile strength [1].
According to the previous studies by Lee et al. [2] and Teraoka et al. [3], the failure modes of nonseismically beamcolumn joints could be classified into three groups: B-failure $\left(V_{n} / V_{u}>1.8\right)$ indicates flexural yielding of beams undergoing large inelastic deformation until ultimate rotational capacity without shear failure in joints; BJ-failure indicates joint failure after initial yielding of beam reinforcement $\left(1 \leq V_{n} / V_{u} \leq\right.$ 1.8); and J series indicate joint failure by shear force without yielding of beam reinforcement $\left(V_{n} / V_{u} \leq 1\right)$, where $V_{n} / V_{u}$ is the ratio of joint shear capacity to joint shear demand evaluated based on the beam yield and hardening mechanism.

For the RC beam-column joints without seismic reinforcement details, several repair and retrofitting methods have been proposed in recent years. Engindeniz et al. [4] grouped several repairing and strengthening techniques as follows: (i) epoxy repair; (ii) removal and replacement of concrete in damaged areas; (iii) concrete jacketing; (iv) concrete masonry unit jacketing; (v) steel jacketing and addition of 
external steel elements; and (vi) strengthening with fiberreinforced polymeric (FRP) composite application.

Shafaei et al. [6] investigated the performance of four nonseismically detailed beam-column joints retrofitted with steel angles, which were mounted using prestressed crossties. This technique prevented the slippage by increasing the joint area of the bottom longitudinal reinforcement of beam; moreover, the plastic hinge was relocated far from the column face, and the shear strength, stiffness, energy dissipated, and ductility capacity were significantly increased up to $50 \%$, $120 \%, 220 \%$, and $220 \%$, respectively.

In addition, El-Amoury and Ghobarah [7] performed the seismic tests on beam-column joints strengthened with glass fiber-reinforced polymers (GFRP). The retrofit strategy included two systems: the first system is used for upgrading the shear strength of the joint with two U-shaped GFRP layers, and the second system is used for upgrading the bondslip of the steel bars. The test results showed that the use of GFRP jacketing significantly enhanced the ductility and the load-carrying capacity of the retrofitted beam-column joints. Besides, the brittle joint shear failure of the retrofitted specimens was also eliminated and the stiffness degradation of the joints was reduced. Particularly, the energy dissipation capacity was increased by up to six times compared to that of nonretrofitted joints.

Moreover, the haunch retrofit solution (HRS) using haunch elements was proposed by Pampanin et al. [8] and several comprehensive tests were performed by Genesio [9] using postinstalled anchors for optimization of the HRS. The main principle of HRS was to relocate the plastic hinge away from the vulnerable panel zone thus enhancing the global response of RC beam-column joints without seismic reinforcement details by altering the hierarchy of strength suitably. These tests had proved the efficiency of the HRS to the hierarchy of strength in beam-column joints in order to prevent brittle joint shear failure and induce the ductile beam failure at much higher lateral loads.

In this study, to develop the seismic retrofitting techniques to beam-column joints in existing concrete buildings in Korea, four half-scale RC exterior beam-column joints were tested. A control specimen is designed to be failed in J-failure, which refers to joint failure before plastic hinges formed at the ends of adjacent beams. Thus, this specimen is associated with low displacement and ductility. Then, two different retrofit strategies were applied to the control specimen: steel jacketing and haunches retrofit solution. The retrofitting methods used in this study emphasize the practical details, architectural characteristics of real buildings, and construction ability of retrofitting methods. All specimens were tested under simulated seismic loading. Based on the test results, the structural performance of control and retrofitted specimens is assessed in terms of various factors: failure mode, hysteretic behavior, drift capacity, and energy dissipation capacity.

\section{Experimental Program}

2.1. Test Specimens. Figure 1 shows a typical RC 10-story building in Korea with $3900 \mathrm{~mm}$ in story height and three

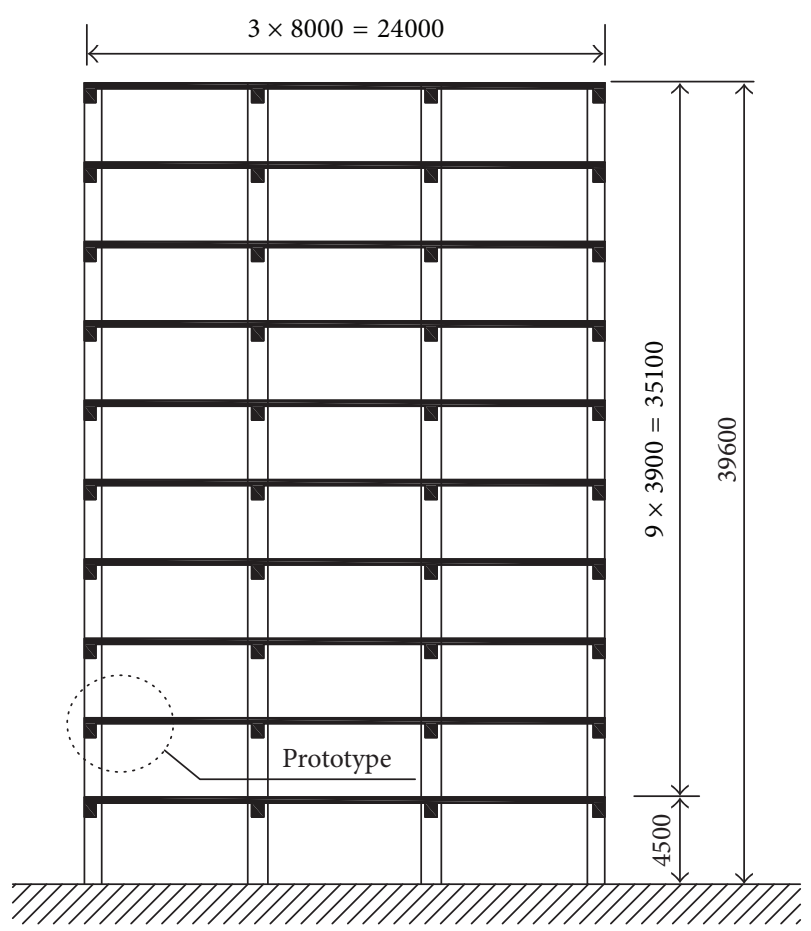

FIGURE 1: A typical RC 10-story building.

bays of $8000 \mathrm{~mm}$. This building was built with a nonseismic reinforcement details, which is generally designed and constructed in Korea during 1970s and 1980s. As reported by Korea National Emergency Management Agency [10], the beam-column joints of old buildings constructed during 1970s and 1980s in Korea do not have seismic reinforcement details; stirrups or ties had standard 90-degree hooks and large spacing, and the anchorage of top longitudinal reinforcing bars of beams was bent down inside the joint regions while the anchorage of bottom longitudinal reinforcing bars was bent down away from joint regions, which might decrease strength and deformation capacity of the joints [10]. All specimens in this study were designed to simulate the exterior beam-column joints in second floor of the building with a half scale.

The control specimen (specimen J) has nonseismic reinforcement details inside the joint region. In this study, to achieve J-failure mode of the control specimen, the design top reinforcement ratio of beams was $2.9 \%$ corresponding to a ratio of joint shear capacity to joint shear demand, $V_{n} / V_{u}$, of 0.73 . For all specimens, for positive bending moment of beams, the bottom longitudinal reinforcement ratios of beams had the same value of $0.43 \%$. The configurations and details of specimen J were presented in Figure 2.

Figure 3 illustrates the schematic drawings of retrofitted specimens. It should be noted that, in test specimens, only a portion of the joint panel zones was retrofitted with retrofit materials to consider the existence of transverse beams and floor slabs in real structures. However, the effect of transverse beam and slab confinement on seismic performance of exterior RC beam-column joints is not clarified so far [11, 12]. Moreover, in this study, the authors consider the worst 


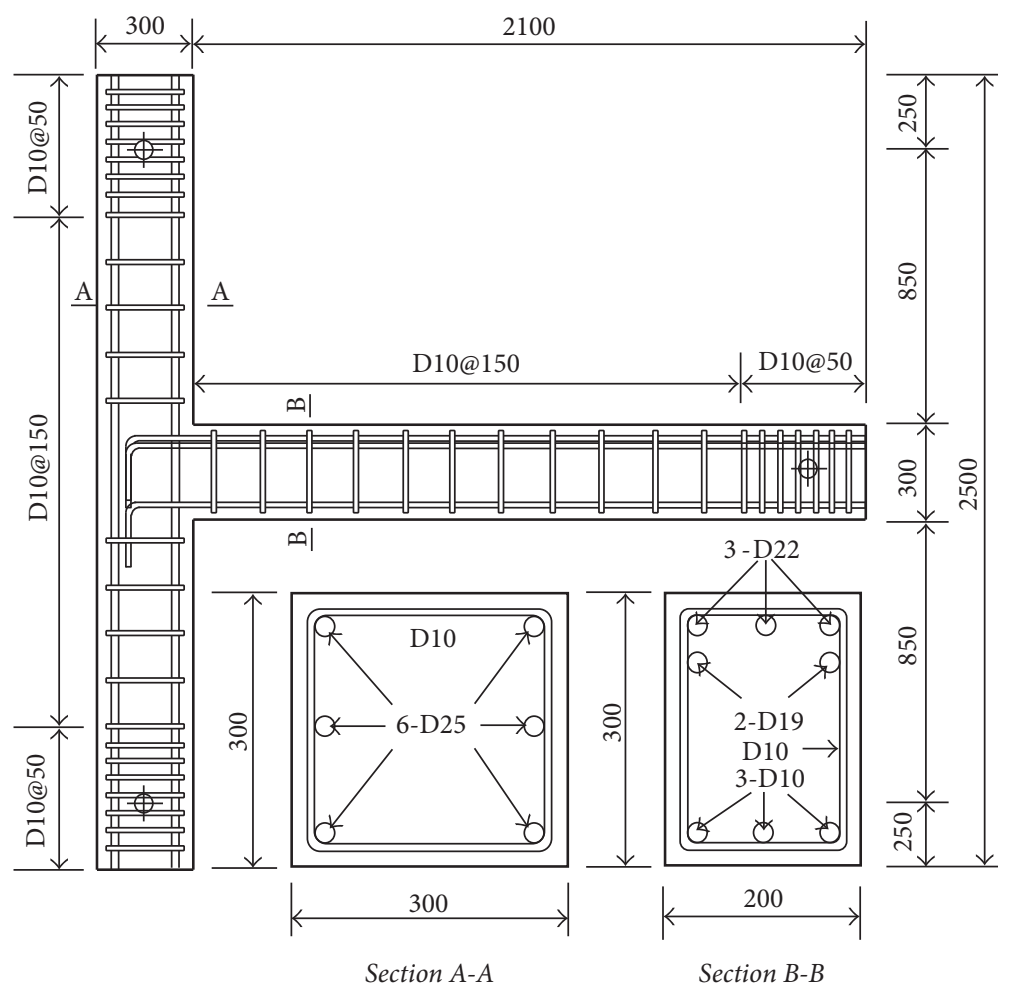

FIGURE 2: Configurations and details of control specimen.

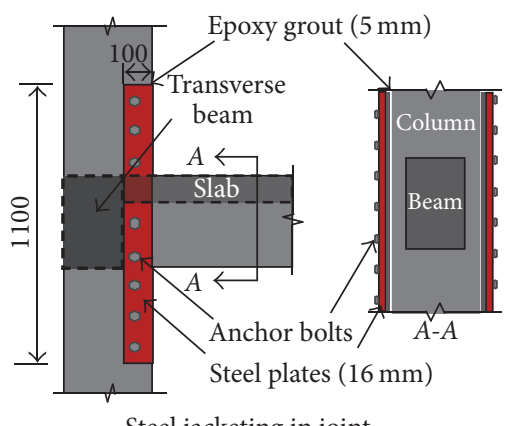

Steel jacketing in joint

(a) Specimen J-S1

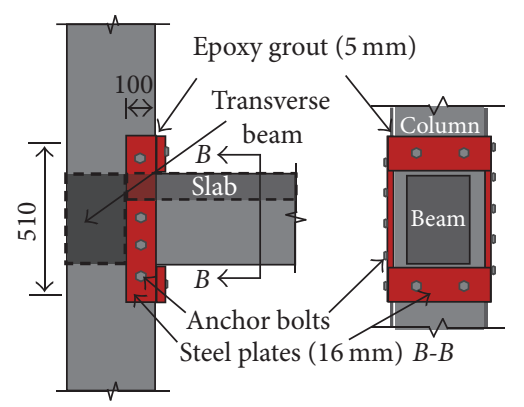

Steel jacketing in joint

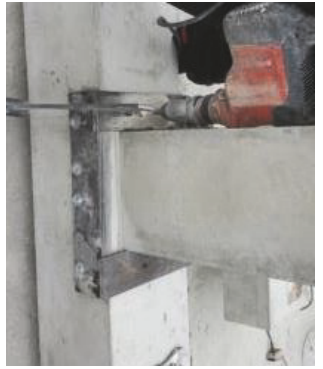

Photo of J-S2

(b) Specimen J-S2

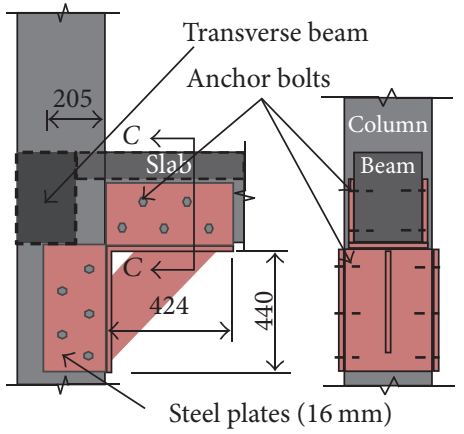

Haunch element details

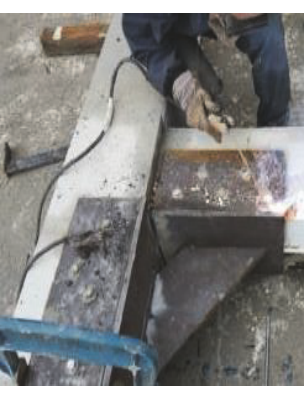

Photo of J-H

(c) Specimen J-H

FIGURE 3: Details of retrofitted specimens. 
TABLE 1: Test results of concrete compressive strength.

\begin{tabular}{|c|c|c|c|c|}
\hline Specimens & $\mathrm{J}$ & $\mathrm{J}-\mathrm{S} 1$ & $\mathrm{~J}-\mathrm{S} 2$ & $\mathrm{~J}-\mathrm{H}$ \\
\hline Testing day (days) & 20 & 21 & 23 & 25 \\
\hline $\begin{array}{l}\text { Concrete compressive } \\
\text { strength } f_{c}^{\prime}(\mathrm{MPa})\end{array}$ & 20.87 & 20.14 & 18.64 & 19.8 \\
\hline
\end{tabular}

circumstance of joints subjected to lateral load without confinement in joint region for rehabilitation purpose. Hence, in this study, the concrete transverse beams and slabs were not included in test specimens.

Figures 3(a) and 3(b) show the details of specimens J-S1 and J-S2, which were strengthened in joints with steel jackets (SS400) having a thickness of $16 \mathrm{~mm}$ and specified yield strength of $400 \mathrm{MPa}$. In specimen J-S1 (Figure 3(a)), two sides of column were attached with steel plates having a length of $1100 \mathrm{~mm}$, which were installed with anchor bolts HILTI HSL$3 \mathrm{M} 12$ (the diameter of $12 \mathrm{~mm}$ and the length of $120 \mathrm{~mm}$ ). Meanwhile, in specimen J-S2, three sides of column were installed with steel plates with bolts as shown in Figure 3(b). It is noted that the surfaces of concrete were covered by a layer of epoxy grout having a thickness of $5 \mathrm{~mm}$ before steel plates were installed. The details of steel jacket design procedure are summarized in Appendix A.

Figure 3(c) shows the details of specimen J-H, which was strengthened using haunch retrofit solution. In this retrofitted technique, a haunch element was only installed at the bottom part of the beam, due to considering the architectural characteristic in real buildings. The haunch element used in this test consisted of three steel plates welded together. The design length of haunch element is $424 \mathrm{~mm}$, which is 0.2 times the length of the beam $(2100 \mathrm{~mm})$, according to the recommendation by Sharma et al. [13]. To connect the haunch element with beam and column, five anchor bolts HILTI HSL-3 M12 (the diameter of $12 \mathrm{~mm}$ and the length of $120 \mathrm{~mm}$ ) at each side of beam and column were used. The details of haunch element design procedure are summarized in Appendix B.

2.2. Materials. To consider the low strength of concrete and steel rebars used in the existing concrete frame buildings based on a Korea investigation report, all specimens were constructed with normal-weight concrete having the design compressive strength of $21 \mathrm{MPa}$. Table 1 showed the average compressive strength of three standard cylindrical specimens for each concrete batch based on the uniaxial compressive tests on the loading day according to KS F 2405 [14].

As for longitudinal and transverse reinforcement, grade 300 (specified yield strength $=300 \mathrm{MPa}$ ) was used. The steel reinforcing bars of D10, D16, D19, and D22 have diameters of $10,16,19$, and $22 \mathrm{~mm}$, respectively. Uniaxial tension tests were performed according to KS B 0802 [15] and 0814 [16], and the actual average yield strengths and ultimate strengths acquired were listed in Table 2.

2.3. Test Setup and Measuring Instruments. Test setup aimed to reproduce the deformed shape and internal forces in beamcolumn joints subjected to cyclic lateral loading. Figure 4
TABLE 2: Test results of reinforcing bars.

\begin{tabular}{lcc}
\hline Reinforcing bars & $\begin{array}{c}\text { Yield tensile } \\
\text { strength } f_{y}(\mathrm{MPa})\end{array}$ & $\begin{array}{c}\text { Ultimate tensile } \\
\text { strength } f_{u}(\mathrm{MPa})\end{array}$ \\
\hline D10 & 405 & 587 \\
D16 & 363 & 549 \\
D19 & 372 & 555 \\
D22 & 383 & 584 \\
\hline
\end{tabular}

illustrates a photo of the test setup. In the figure, the column of the join is placed in a vertical position and the beam is placed in a horizontal position. The top and the bottom ends of the columns are connected to hydraulic actuator and strong floor, respectively. Moreover, lateral cyclic loading is applied to the top of the columns by a $500 \mathrm{kN}$ hydraulic actuator in order to simulate earthquake loading. The pin connection at the end of a beam is supported by an axial steel link connected at its base. A lateral support system is connected to a reaction frame to prevent out-of-plane movement of test specimens.

The lateral loading is applied to specimens at the tip of columns to simulate earthquake loading by a $500 \mathrm{kN}$ hydraulic actuator. The cyclic loading history is shown in Figure 5 according to the specification of ACI 374.2R-13 [17], with two cycles at each drift ratio level of $0.25 \%, 0.5 \%, 0.75 \%$, $1 \%, 2 \%, 3 \%, 4 \%, 5 \%$, and so on until failure. In this study, no axial force was applied on the top of columns [18]. However, further investigation on the effect of the column compression force on the behavior of beam-column joints is necessary.

Figures 6 and 7 present the location of linear variable displacement transducers (LVDTs) and strain gauges attached to specimens, respectively. A LVDT was placed at the upper end of the column to measure the total lateral displacement. Moreover, shear deformation of panel zones was measured by a set of LVDTs, as shown in Figure 6.

For each specimen, a total of 14 electrical resistance strain gauges were attached to longitudinal and transverse reinforcement of a beam and two columns around a panel zone to measure the magnitude of reinforcing bars strains developed during different loading stages. As shown in Figure 7, the column reinforcing bars were gauged at the location next above the connection part (strain gauges number 1 and number 2). The beam reinforcing bars were gauged at two different locations: one is adjacent to the joint part (strain gauges numbers $3,4,5$, and 6); and the other is inside the joints (strain gauges numbers $7,8,9,10,11$, and 12) to check the yield penetration of beam reinforcement. The transverse reinforcement of columns and beams was gauged to monitor the strains (strain gauges number 13 and number 14). Both the displacement and strain data were collected using the data acquisition system.

\section{Test Result Analysis and Discussions}

3.1. Hysteretic Behavior. Figure 8 shows the relationship between the applied lateral load and drift ratio of test specimens, which is the ratio between the lateral displacement 


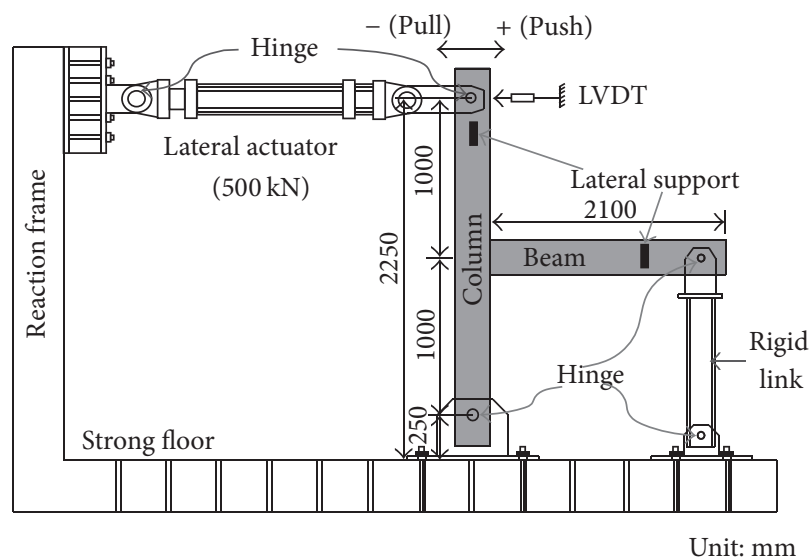

(a) Diagram

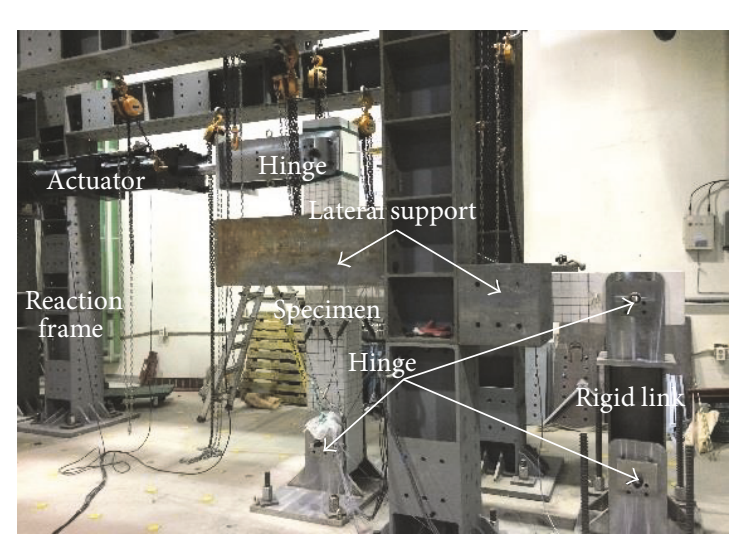

(b) Photograph of test setup

FIGURE 4: Test setup of specimens.

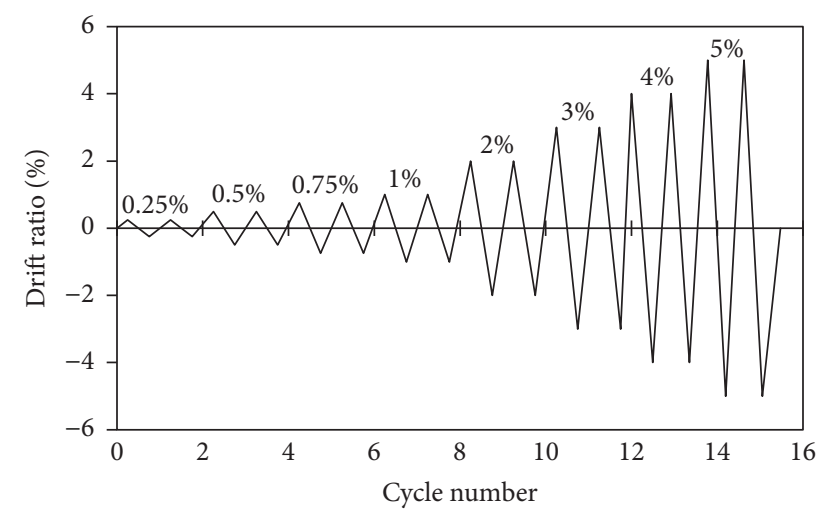

Figure 5: Loading history.

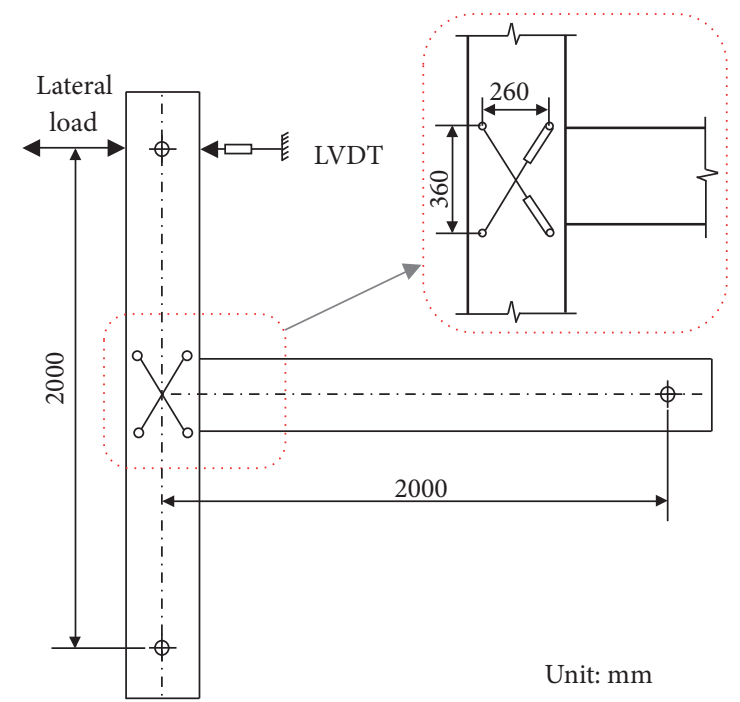

FIGURE 6: Location of LVDTs in specimens.

and the net column height $(2000 \mathrm{~mm})$. The nominal lateral load-carrying capacities $\left(P_{n}^{+}\right.$and $\left.P_{n}^{-}\right)$of each specimen is calculated based on beam flexural yielding. In each figure, the

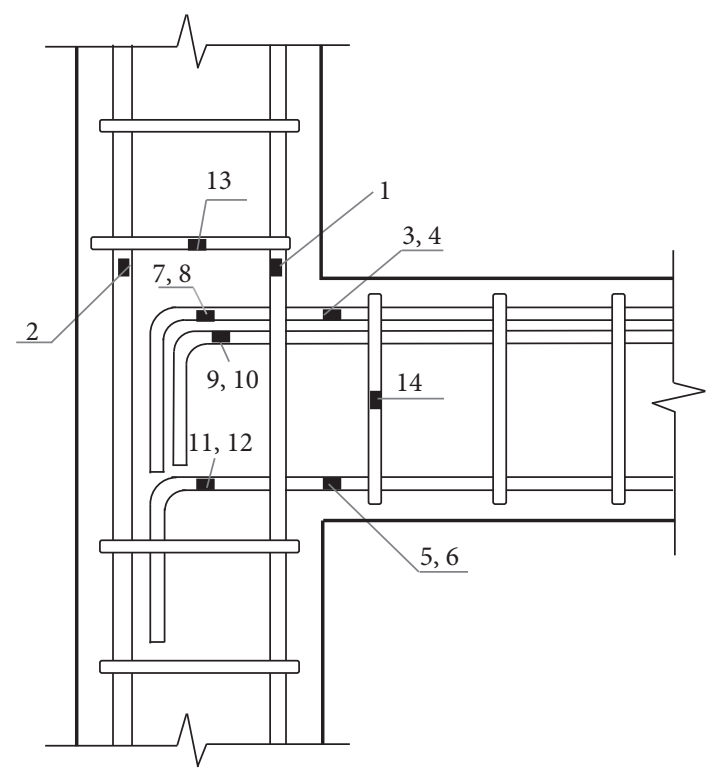

FIGURE 7: Location of strain gauges in specimens.

hysteretic behavior of retrofitted specimens is presented and compared with control specimen J.

From Figure 8, for the negative loading, in which top longitudinal reinforcement of beams was subjected to tension, the maximum lateral force obtained from test results of the control specimen $\mathrm{J}$ is $-45.12 \mathrm{kN}$, which is less than the value predicted based on beam nominal flexural strength $\left(P_{u}{ }^{-}=-54.32 \mathrm{kN}\right)$. Moreover, the strength degradation was also observed after reaching peak lateral load in negative direction. This failure could be classified into shear failure of joints.

Specimens J-S1 and J-S2 showed similar maximum later forces $(-57.27 \mathrm{kN}$ and $-56.31 \mathrm{kN}$, resp.), which were greater than that of specimen J approximately $25 \%$, and reached the value predicted based on beam nominal flexural strength 


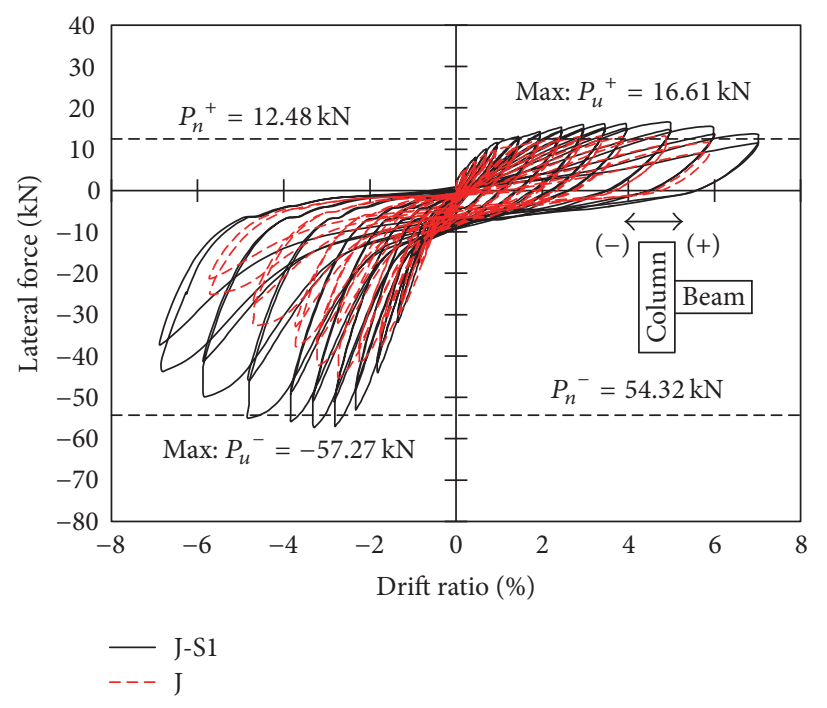

(a) Specimen J-S1

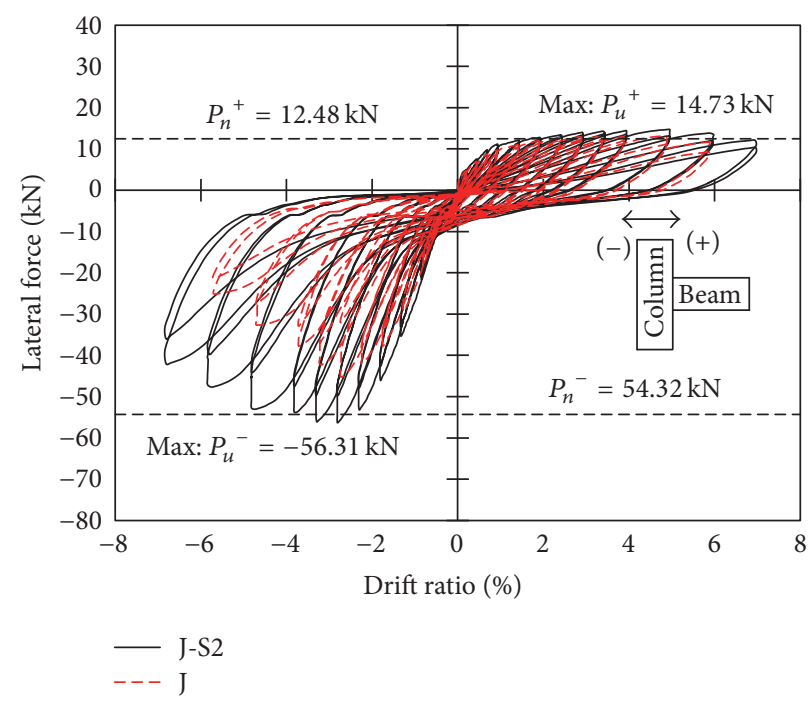

(b) Specimen J-S2

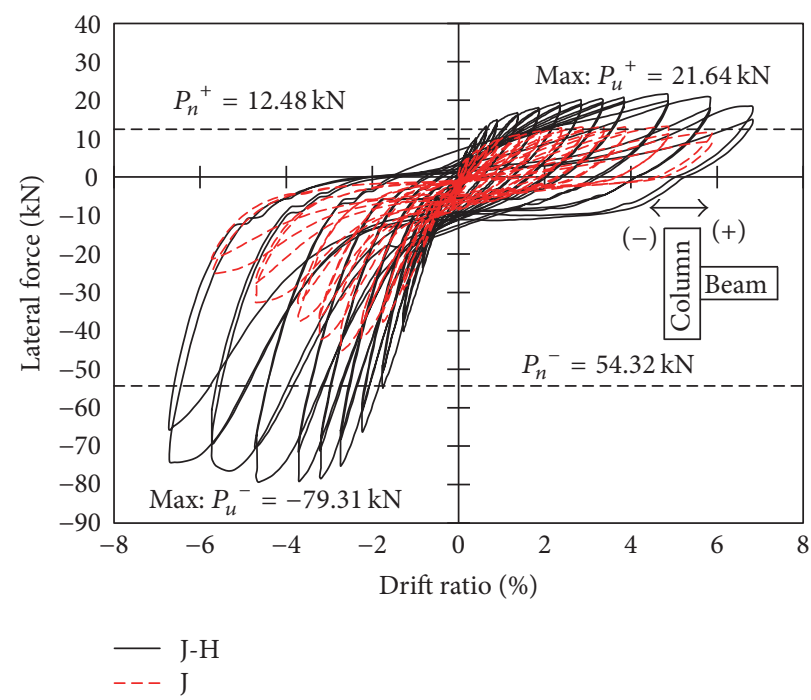

(c) Specimen $\mathrm{J}-\mathrm{H}$

FIGURE 8: Lateral load-drift ratio relationships of test specimens.

(Figures 8(a) and 8(b)). Particularly, in case of J-H specimen, the maximum lateral load-carrying capacity observed was $-79.31 \mathrm{kN}$, which was $76 \%$ greater than that of control specimen. Moreover, the strength degradation after peak load in $\mathrm{J}-\mathrm{H}$ was insignificantly compared to J-S1 and J-S2. For example, in $\mathrm{J}-\mathrm{H}$, at $-6.8 \%$ drift ratio, the lateral load decreased by almost $6.44 \%$ compared to the maximum value, while these figures for the cases of J-S1 and J-S2 are $23.78 \%$ and $25.34 \%$, respectively.

3.2. Failure Modes. The damage and cracking features of test specimens observed at the end of loadings are shown in Figure 9. In specimen J (Figure 9(a)), at the end of loading, numerous inclined cracks with a large width had developed. Moreover, no damage is observed at the plastic hinge of the beam end with few small flexural cracks in beam. In addition, vertical cracks at the interface of column and joint are observed at the end of loading.

In specimens J-S1 and J-S2 (Figures 9(b) and 9(c)), inclined cracks with a large width are developed in the joint outside the steel jacketing retrofitted region at the end of loading. However, the number of crack is slightly fewer than that of specimen J. Similar to J, no damage at the plastic hinge of the beam end and vertical cracks are observed in case of $\mathrm{J}-\mathrm{S} 1$ and $\mathrm{J}-\mathrm{S} 2$.

The observed cracking pattern in case of $\mathrm{J}-\mathrm{H}$ is show in Figure 9(d). It appears that few inclined cracks with a small width are developed in joint. However, numerous flexural and diagonal cracks are developed in beam. In particular, at the location at which diagonal haunch connected to beam, steel rebar buckling and concrete spalling are observed at the end of loading, which lead to the collapse of specimen J-H. 


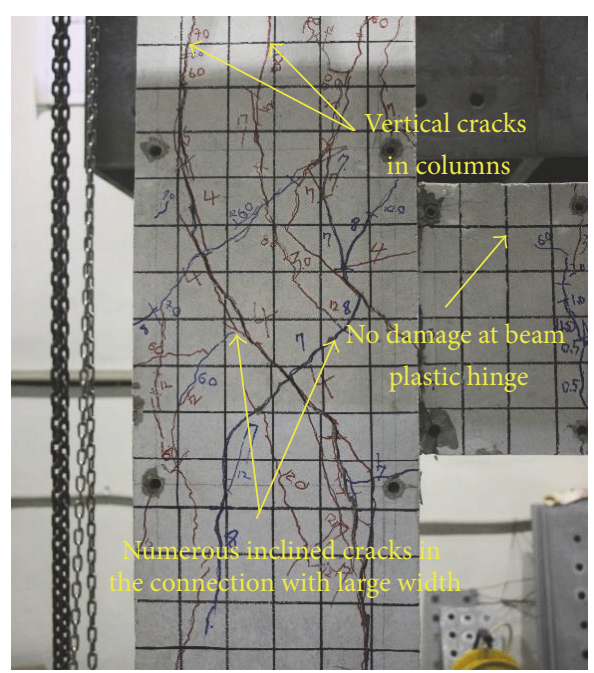

(a) Specimen J

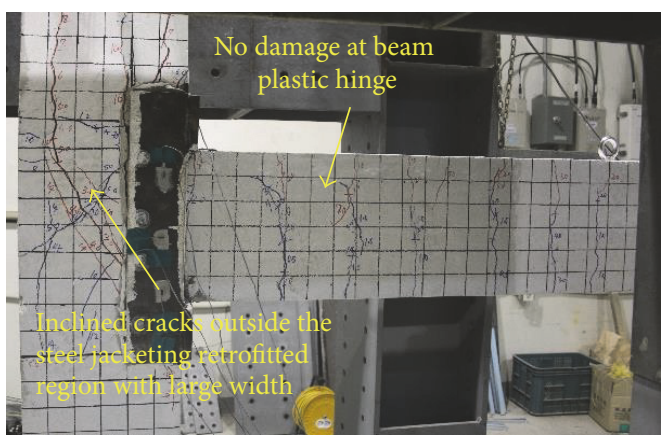

(c) Specimen J-S2

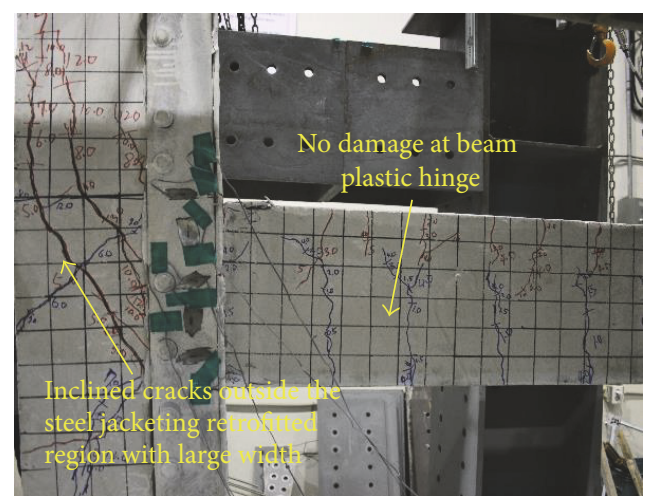

(b) Specimen J-S1

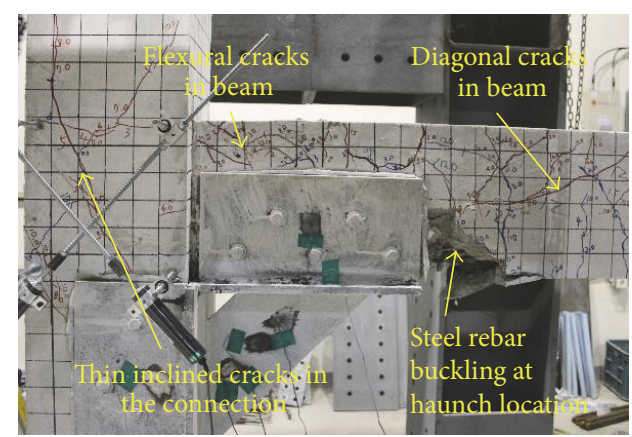

(d) Specimen J-H

FIgURE 9: Failure modes of test specimens at the end of loading.

This proved that plastic hinge was developed in beam and relocated at the joint, between diagonal haunch and bottom beam.

3.3. Shear Deformation of the Joints. The average shear deformation, $\gamma$, in joints was evaluated from test measurements following this equation (Figure 10):

$$
\gamma=\gamma_{1}+\gamma_{2}=\frac{\sqrt{a^{2}+b^{2}}}{2 a b}\left(\delta_{\mathrm{I}}-\delta_{\mathrm{II}}\right),
$$

where $\gamma$ is average shear deformation of joints; $\gamma_{1}$ and $\gamma_{2}$ are deformation angles; $a$ and $b$ are defined in Figure 10; $\delta_{\mathrm{I}}$ and $\delta_{\text {II }}$ are the changes in the diagonal lengths measured by LVDT I and II ("+" for lengthening and "-" for shortening).

Figure 11 shows the variation of the joint shear deformation of specimens $\mathrm{J}$ and $\mathrm{J}-\mathrm{H}$ according to drift ratio. It is noted that the joint shear deformation of specimens J-S1 and J-S2 is not presented here due to the missing data. It can be seen that the contribution of the joint shear deformation is the least in J-H specimen. Meanwhile, control specimen J shows the greatest contribution of joint shear deformation.

3.4. Energy Dissipation Capacities. The dissipated energy of test specimens was defined as the area enclosed by a hysteretic loop at each loading cycle, $E_{d}$, in accordance with ASCE 41-13 [19]. Figure 12 shows the cumulative energy dissipated according to the loading cycle of test specimens in this study. From the figure, in the elastic range, all specimens showed almost the same trend and magnitude of energy dissipation. However, in inelastic range, specimen $\mathrm{J}-\mathrm{H}$ retrofitted by haunch element illustrated the highest increase of dissipated energy. The cumulative energy dissipated at 13th loading cycle was $29.74 \mathrm{kNm}$, which was approximately 2 times more than that of control specimen J. In addition, specimens J-S1 and J-S2 showed almost the same value of cumulative energy dissipation through the test, which was 1.4 times more than that of control specimen J in inelastic range.

3.5. Strain Profiles of Flexural Rebars. The strain profiles of the top longitudinal reinforcement of beam were illustrated in Figure 13 for outside (Gauge 1) and inside (Gauge 2) the joint regions. As shown in Figure 13(a), for negative loading direction, at which the top rebars were subjected to tension, the top rebars outside the joint of control specimen $J$ do not reach the yield strain $(0.0015 \mathrm{~mm} / \mathrm{mm})$. This confirmed the reason why the maximum negative lateral load does not reach the theoretical nominal value. However, the top rebars outside the joint of the retrofit specimens were absolutely yielded, and 


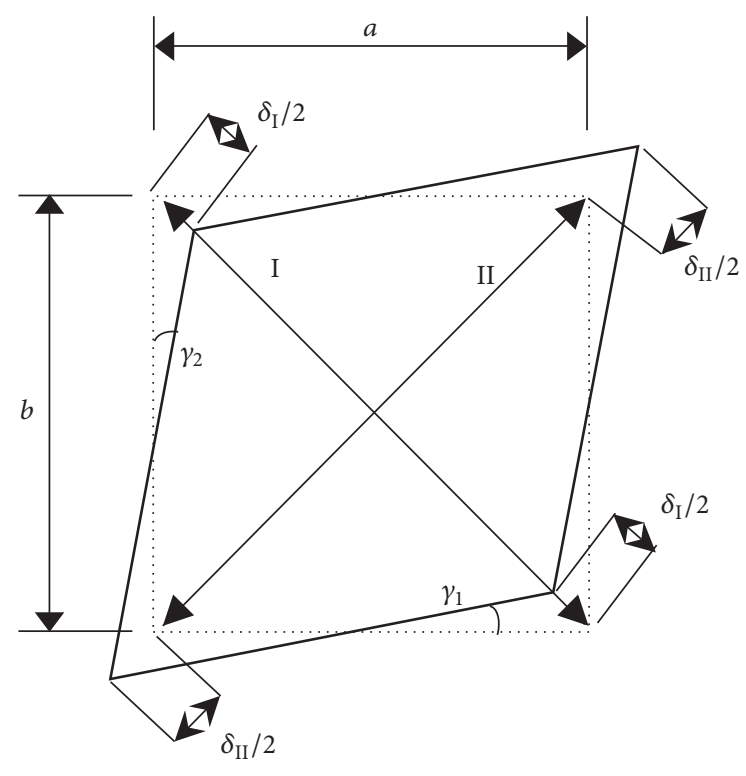

FIGURE 10: Evaluation of joint shear deformation.

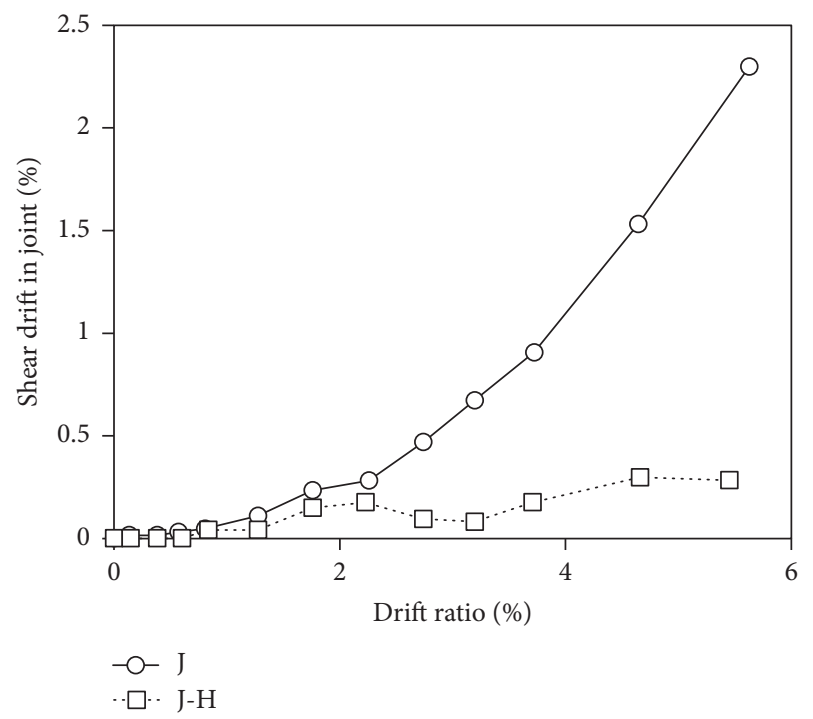

FIGURE 11: Joint shear deformation of test specimens.

the maximum negative load exceeded the theoretical nominal value calculated by beam flexural strength. In all the cases, top longitudinal rebars of beam inside the joints were not yielded (Figure 13(b)). Particularly, the strain of top rebars of specimen J-H was smaller than the others corresponding to each of the drift ratios.

The strain profiles of the bottom longitudinal reinforcement of beam were illustrated in Figure 14 for outside (Gauge 3 ) and inside (Gauge 4) the joint regions. From the figure, for positive lateral loading direction, the bottom bars outside and inside the joints of all specimens exceeded the yield strain. On the contrary, for negative loading direction, the strains of bottom bars of all specimens do not exceed the yield strain.

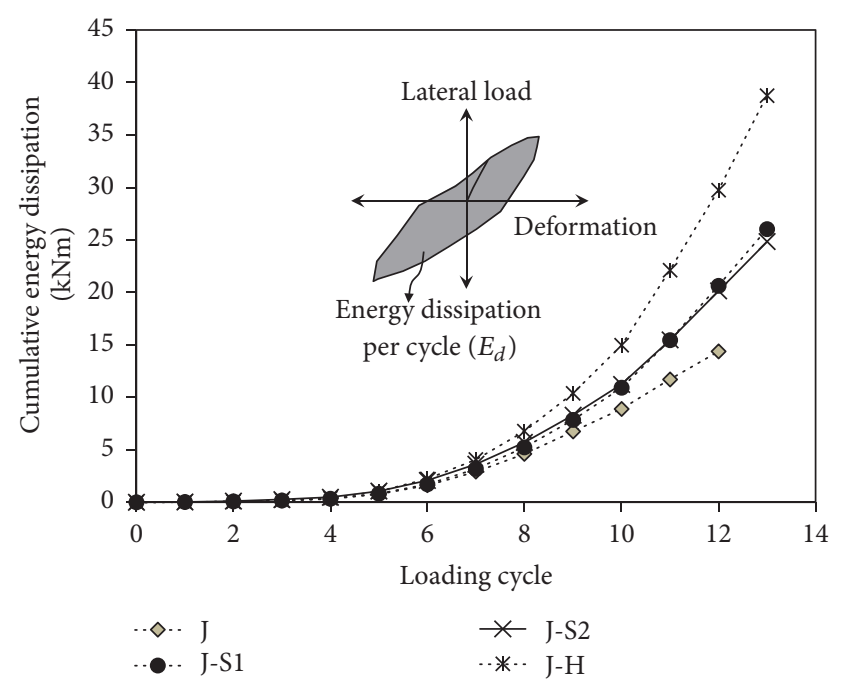

FIgURE 12: Cumulative dissipated energy of test specimens.

\section{Conclusion}

This article presented studies three half-scale retrofitted exterior RC beam-column joints and one control specimen. The major results are summarized as follows:

(1) The control specimen showed numerous inclined cracks in joint regions with large crack width. The maximum lateral load cannot reach the nominal value predicted by beam flexural strength. Moreover, the strength degradation was severe after reaching peak later load.

(2) Specimens J-S1 and J-S2 retrofitted with steel jacketing method showed similar behavior. In negative loading direction, the maximum lateral load increased $25 \%$ more than control specimen and reached the nominal value predicted by beam flexural strength. Particularly, specimen J-H retrofitted using haunch element showed $76 \%$ increased maximum lateral load, which is much larger than control specimen. Moreover, the strength degradation after peak strength was insignificant compared to J-S1 and J-S2.

(3) The failure mode of control specimen was governed by shear failure in joint region with numerous inclined cracks with a large width. However, in J-S1 and J-S2, the number of cracks was slightly smaller than that of specimen J. In particular, few inclined cracks with a small width were developed in joint of specimen $\mathrm{J}-\mathrm{H}$, and numerous flexural and diagonal cracks were developed in beam.

(4) In the case of J-H, shifting of hinge location from joint to beam is a good indicator of good retrofit scheme.

(5) The shear deformation in joint region in case of specimen $\mathrm{J}-\mathrm{H}$ decreased significantly compared to control specimen J. 


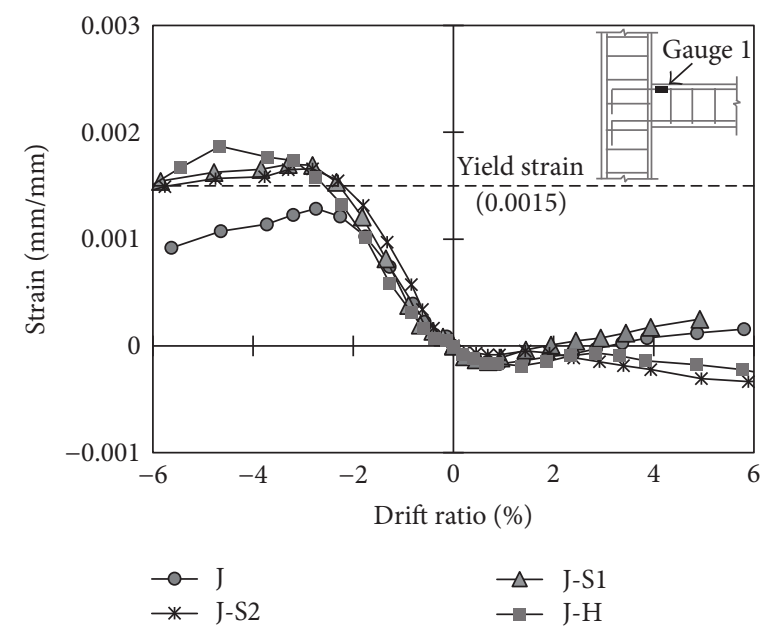

(a) Outside joint regions

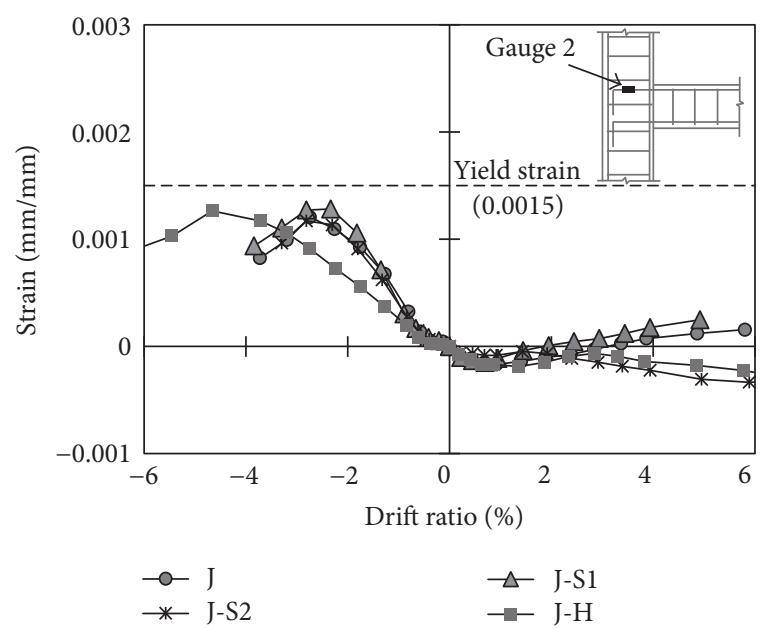

(b) Inside joint regions

FIGURE 13: Strain profiles of the top rebars.

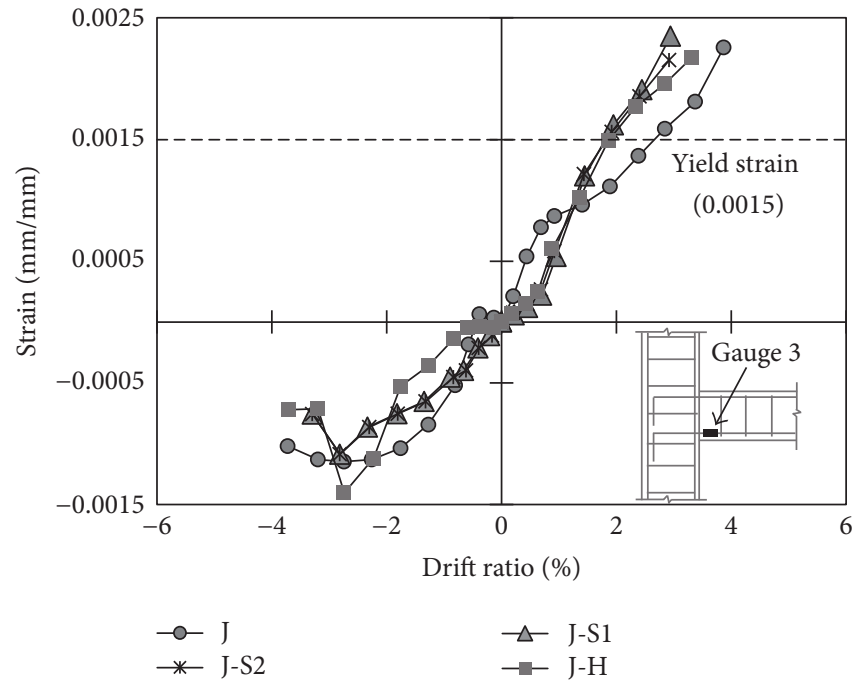

(a) Outside joint regions

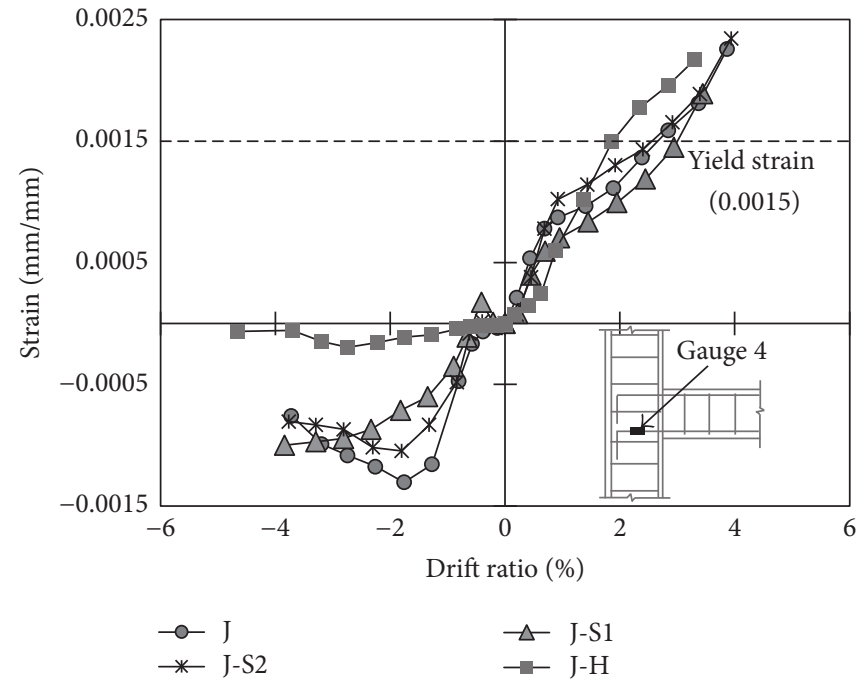

(b) Inside joint regions

FIGURE 14: Strain profiles of the bottom rebars.

(6) All retrofitted specimens showed increased energy dissipation capacities and decreased damping ratios, compared to control specimen.

(7) The strain of top longitudinal rebars of beam of retrofitted specimens exceeded the yield strain. Meanwhile, the strain of top longitudinal rebars of beam of control specimen does not reach the yield strain.

\section{Appendix}

\section{A. Steel Jacket Design of Beam-Column Joints}

The steel jacketing retrofit strategy of beam-column joints is to provide the residual strength of $0.5 V_{n}$, where $V_{n}$ is the joint shear strength, which is determined following ACI 352R-02 [20]:

$$
V_{n}=0.083 \gamma \sqrt{f_{c}^{\prime}} b_{j} h_{c}
$$

where $f_{c}^{\prime}$ is the concrete compressive strength and $b_{j}$ and $h_{c}$ are the effective joint width and the depth of the column in the direction of the joint shear being considered, respectively.

Thus, shear strength, $V_{s}$, provided by steel jackets should be greater than $0.5 V_{c}$ :

$$
V_{s} \geq 0.5 V_{c}=0.0415 \gamma \sqrt{f_{c}^{\prime}} b_{j} h_{c} .
$$




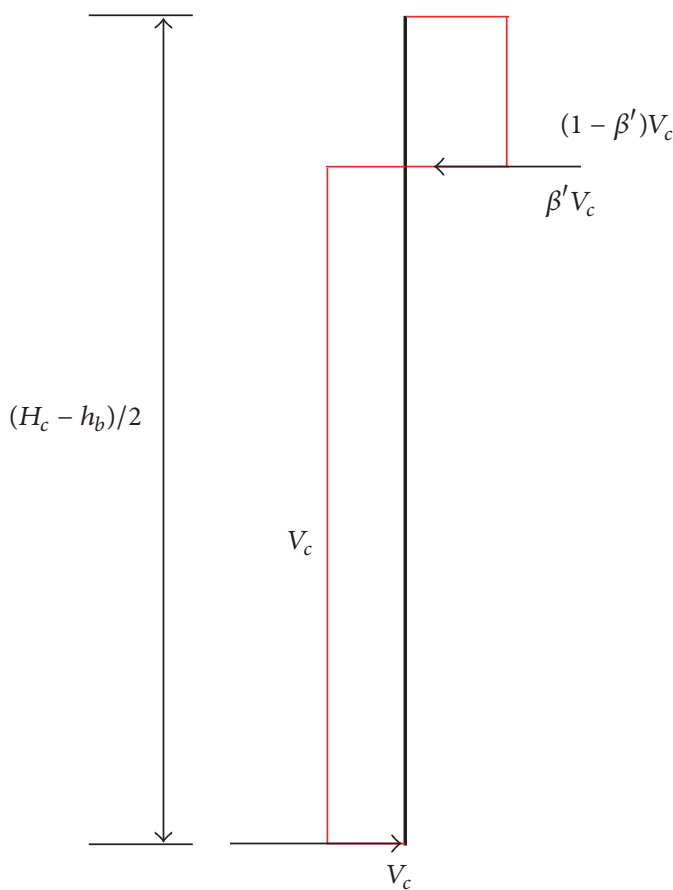

(a) Shear diagram of column

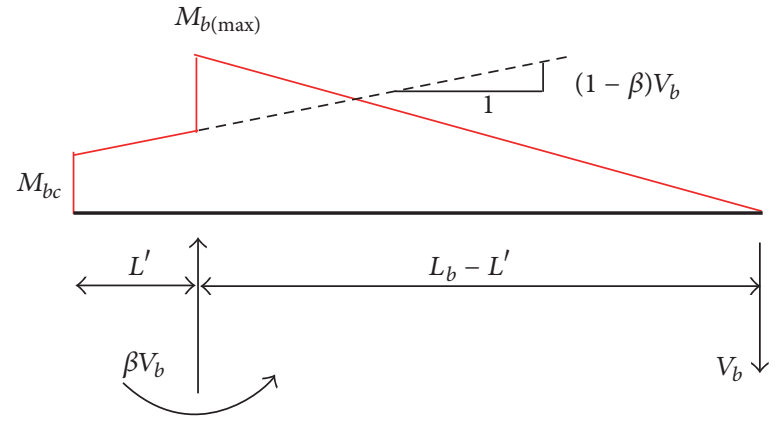

(b) Moment diagram of beam

FIGURE 15: Shear and moment diagram of beam-column joints retrofitted by haunch elements [5].

Besides, $V_{s}$ is determined in accordance with Eurocode 8-3 [21]. For safety factor, only $50 \%$ of yield strength of the steel jackets is used:

$$
V_{s}=0.5 h_{c} \frac{2 t_{s} b_{s}}{s} f_{y t, d}(\cot \theta+\cot \beta) \sin \beta,
$$

where $t_{s}$ is the thickness of the steel jackets, $b_{s}$ is the width of the steel jackets, $s$ is the space of the steel jackets $\left(b_{s} / s=1\right.$, in the case of continuous steel plates), $\theta$ is the strut inclination angle, $\beta$ is the angle between the axis of the steel jackets and the axis of the member $\left(\beta=90^{\circ}\right.$, in the case of continuous steel plates), and $f_{y t, d}$ is the design yield strength of the steel jackets.

\section{B. Haunch Element Design of Beam-Column Joints}

According to previous research of Chen (2006) [5], haunch elements will change the shear and moment distribution in the adjacent beams and columns of the joints, as shown in Figure 15. In this figure, the bending moment $\left(M_{b c}\right)$ and shear in column $\left(\beta^{\prime} V_{C}\right)$ at the interface of the joints were calculated as follows:

$$
\begin{aligned}
M_{b c} & =M_{b(\max )}+(1-\beta) V_{b} L^{\prime}-\frac{h_{b} \beta V_{b}}{2 \tan \alpha}, \\
V_{c}^{\prime} & =\left(1-\beta^{\prime}\right) V_{c}, \\
\beta & =\frac{b}{a}\left(\frac{6 L h_{b}+3 a h_{b}+6 b L+4 a b+2 I_{b} b^{3} / I_{c} a H_{c}+3 I_{b} H L_{b} b^{3} / 2 I_{c} a^{2} H_{c}+3 I_{b} h_{c} H L_{b} b^{2} / I_{c} a^{2} H_{c}}{3 h_{b}+6 b h_{b}+4 b^{2}+12 E_{c} I_{b} / 2 K_{d} a \cos ^{2} \alpha+6 I_{b} b^{2} / a^{2} A_{c}+2 I_{b} h_{c} b^{2} / I_{c} a+3 I_{b} h_{c} b^{2} / I_{c} a^{2}+3 I_{b} h_{c}^{2} b^{3} / 2 I_{c} a^{3}}\right), \\
\beta^{\prime} & =\beta\left(\frac{H_{c}}{L_{b} \tan \alpha}\right), \\
K_{d} & =\frac{E_{s} A_{d}}{L_{h}}, \\
L_{h} & =\sqrt{a^{2}+b^{2}},
\end{aligned}
$$




$$
\begin{gathered}
H=H_{c}-h_{b}-2 b, \\
L=L_{b}-h_{c}-2 a,
\end{gathered}
$$

where $V_{u}$ is the joint shear demand calculated based on the beam yield and hardening mechanism. $M_{b(\max )}$ is the maximum bending moment of the beam; $V_{b}$ is the shear force of the beam; $\beta$ and $\beta^{\prime}$ are the factors representing the effectiveness of the retrofit solution by determining the redistribution of the shear between the beam, column, and haunch elements in the joint; $a$ and $b$ are the projected length of the haunch elements on the beam and column, respectively; $h_{b}$ is the depth of the beam; $I_{b}$ and $I_{c}$ are the effective inertial moment of the beam and column, respectively; $\alpha$ is the angle between beam and diagonal haunch element; and $K_{d}$ is the stiffness of the haunch elements.

\section{Conflicts of Interest}

The authors (Cong-Thuat Dang and Ngoc-Hieu Dinh) declare that there are no conflicts of interest regarding the publication of this paper.

\section{Acknowledgments}

This paper is supported by Project NRF-2014RIAIA2053499 of the National Research Foundation of Korea Grant Funded by the Korean Government, Korea, and by The University of Danang, Vietnam, under the Research Project no. D2015-02135. These financial aids are gratefully acknowledged.

\section{References}

[1] J. P. Moehle and S. A. Mahin, "Observations on the behavior of reinforced concrete buildings during earthquakes," in Earthquake-Resistant Concrete Structures: Inelastic Response and Design, S. K. Ghosh, Ed., ACI publication SP-127, 1991.

[2] J. Y. Lee, J. Y. Kim, and G. J. Oh, "Strength deterioration of reinforced concrete beam-column joints subjected to cyclic loading," Engineering Structures, vol. 31, no. 9, pp. 2070-2085, 2009.

[3] M. Teraoka, Y. Kanoh, S. Sasaki, and K. Hayashi, "An estimation of ductility in interior beam-column sub-assemblages of reinforced concrete frames," Journal-Society of Materials Science, vol. 45, no. 9, pp. 1033-1041, 1996.

[4] M. Engindeniz, L. F. Kahn, and Z. Abdul-Hamid, "Repair and strengthening of reinforced concrete beam-column joints: State of the art," ACI Structural Journal, vol. 102, no. 2, 2005.

[5] T. H. Chen, Development of a low invasive seismic retrofit solution for under-designed frame systems based on a metallic haunch [Diss. MS Thesis], University of Canterbury, Christchurch, New Zealand, 2006.

[6] J. Shafaei, A. Hosseini, and M. S. Marefat, "Seismic retrofit of external RC beam-column joints by joint enlargement using prestressed steel angles," Engineering Structures, vol. 81, pp. 265288, 2014.
[7] T. El-Amoury and A. Ghobarah, "Seismic rehabilitation of beam-column joint using GFRP sheets," Engineering Structures, vol. 24, no. 11, pp. 1397-1407, 2002.

[8] S. Pampanin, C. Christopoulos, and T. H. Chen, "Development and validation of a metallic haunch seismic retrofit solution for existing under-designed rc frame buildings," Earthquake Engineering \& Structural Dynamics, vol. 35, no. 14, pp. 1739-1766, 2006.

[9] G. Genesio, Seismic assessment of RC exterior beam-column joints and retrofit with haunches using post-installed anchors [Ph.D. thesis], 2012.

[10] Seismic Simulation Test Center of Pusan National University, Development of Technologies for Improvement of Seismic Performance on the Existing Low-rise Buildings, National Emergency Management Agency, 2011, (Korean).

[11] L. M. Megget, "Cyclic behavior of exterior reinforced concrete beam-column joints," Bulletin of New Zealand National Society for Earthquake Engineering, vol. 7, no. 1, pp. 22-47, 1974.

[12] S. M. Uzumeri, "Strength and ductility of cast-in-place beamcolumn joints," in Proceedings of the Annual Convention, Symposium on Reinforced Concrete Structures in Seismic Zones, The American Concrete Institute, San Francisco, Calif, USA, 1974.

[13] A. Sharma, G. R. Reddy, R. Eligehausen, G. Genesio, and S. Pampanin, "Seismic response of reinforced concrete frames with haunch retrofit solution," ACI Structural Journal, vol. 111, no. 3, pp. 673-684, 2014.

[14] KS F 2405. Standard Test Method for Compressive Strength of Concrete. Korean Standard Information Center; 2010.

[15] KS B 0802. Method of Tensile Test for Metallic Materials. Korean Standard Information Center; 2013.

[16] KS B 0814. Method of Tensile Test for Metallic Materials. Korean Standard Information Center; 2001.

[17] ACI 374.2R-13, "Guide for Testing Reinforced Concrete Structural Elements Under Slowly Applied Simulated Seismic Loads," ACI Committee, vol. 374, 2013.

[18] C. P. Pantelides, C. Clyde, and L. D. Reaveley, "Performancebased evaluation of reinforced concrete building exterior joints for seismic excitation," Earthquake Spectra, vol. 18, no. 3, pp. 449-480, 2002.

[19] ASCE/SEI 41-13. Seismic Evaluation and Retrofit of Existing Buildings. American Society of Civil Engineering; 2013.

[20] ACI 352R, 2002. Recommendations for Design of BeamColumn Connections in Monolithic Reinforced Concrete Structures. American Concrete Institute, Farmington Hills, Michigan.

[21] Eurocode 8. Design of structures for earthquake resistance Part 3: Assessment and retrofitting of buildings. European Committee for Standardization, CEN, Brussels, Belgium; 2005. 


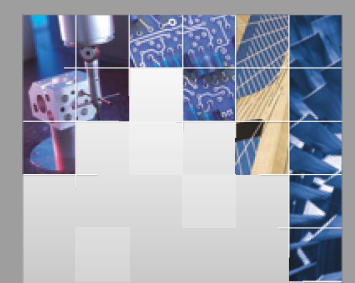

\section{Enfincering}
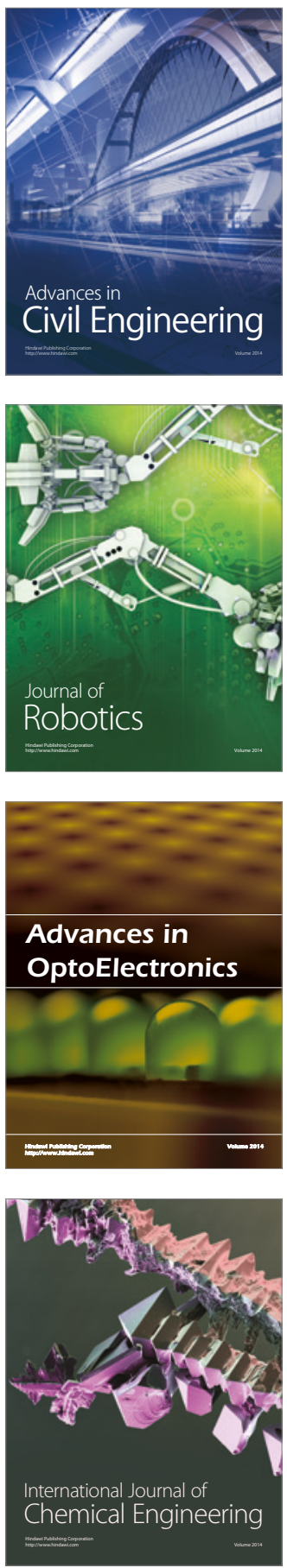

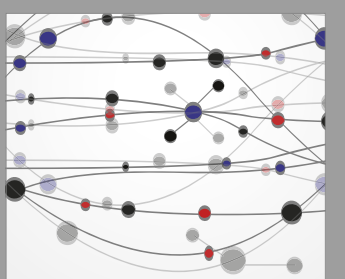

The Scientific World Journal

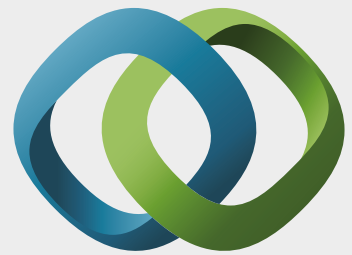

\section{Hindawi}

Submit your manuscripts at

https://www.hindawi.com
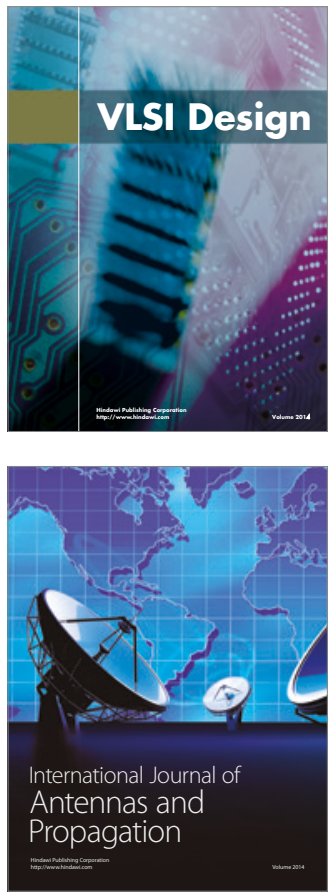

\section{Rotating}

Machinery
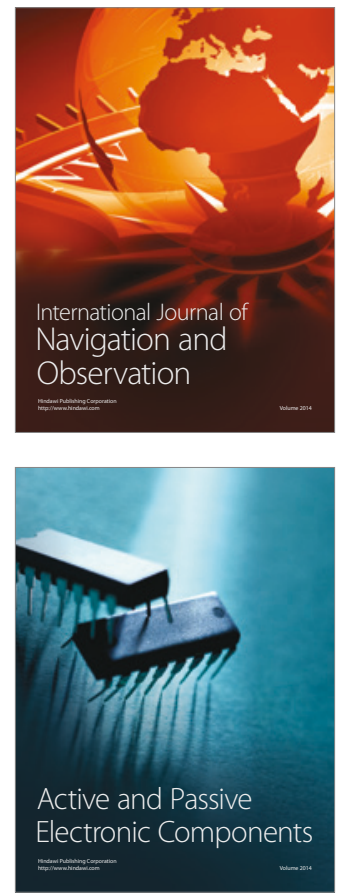
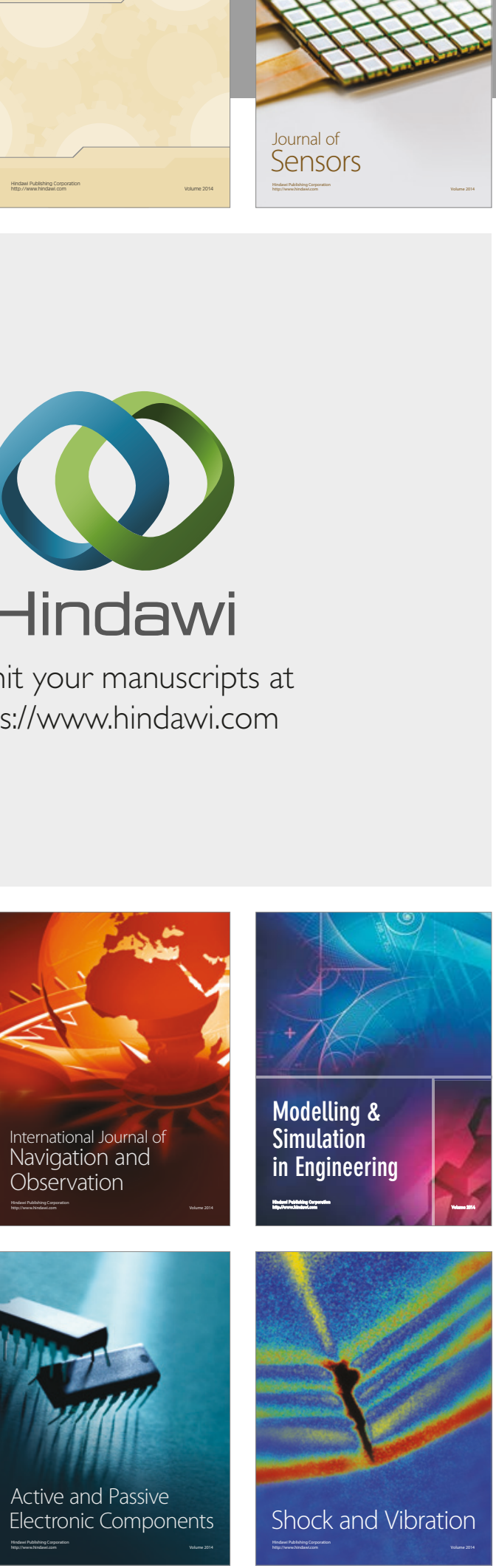
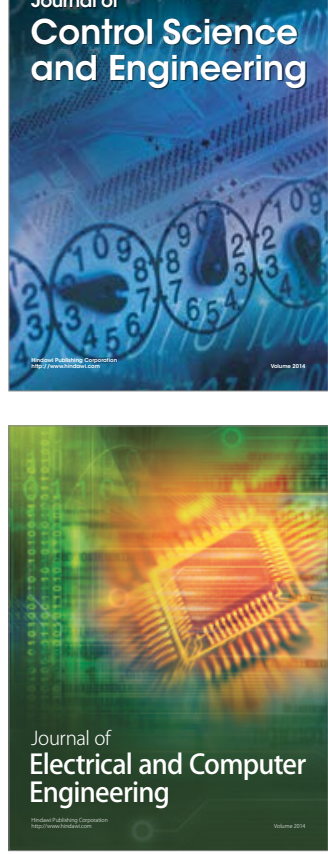

Distributed

Journal of

Control Science

and Engineering
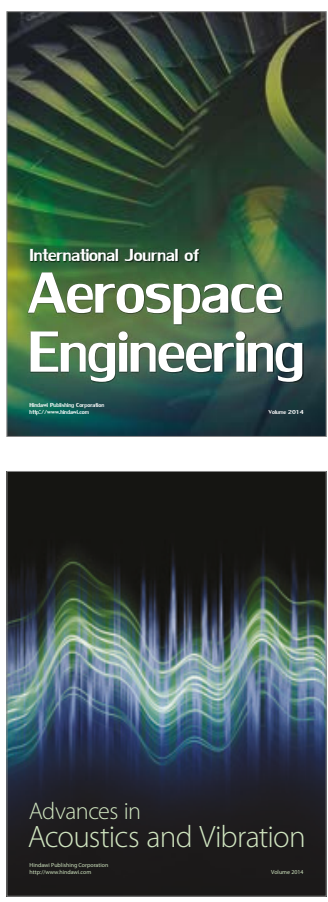

Sensor Networks 